\section{Unknown syndrome: congenital heart disease, choanal stenosis, short stature, developmental delay, and dysmorphic facial features in a brother and sister}

SUMMARY We report a brother and sister born to nonconsanguineous parents. They both had an atrial septal defect and ventricular septal defect. In addition they had short stature, microcephaly, developmental delay, and the same dysmorphic facial appearance of a short nose, epicanthic folds, a long philtrum, and narrow upper lip. The boy had bilateral choanal hypoplasia and stenosis.

\section{Case reports}

Case 1, a girl, was born at term after a normal pregnancy and delivery. The parents were non-consanguineous and this was their first pregnancy. Her weight was $2400 \mathrm{~g}$ ( 3 rd centile), length $50 \mathrm{~cm}$ (50th centile), and head circumference $33 \mathrm{~cm}$ (10th centile). There were no neonatal problems. At 10 months she was investigated for failure to thrive. She weighed $5.5 \mathrm{~kg}(2 \mathrm{~kg}<3 \mathrm{rd}$ centile) and had difficulty sucking from a bottle. One examination noted mild hepatic enlargement but systemic examination was otherwise normal. Investigations showed bilateral vesicoureteric reflux.

On review at three years her height was $76.0 \mathrm{~cm}$ $(10 \mathrm{~cm}<3 \mathrm{rd}$ centile) and her head circumference was $46.5 \mathrm{~cm}$ ( 2 nd centile). There was developmental delay. She could stand unsupported but could not walk, and spoke several words with meaning. Examination of her face showed a prominent metopic suture, apparently widely spaced eyes, marked epicanthic folds, a short nose, long philtrum, narrow upper lip, and low set, posteriorly rotated ears (fig 1). She had short fingers with brittle, spoon shaped nails on all fingers and toes. Chromosome analysis, using Giemsa banding, showed a normal female $46, \mathrm{XX}$ karyotype.

At the age of three years seven months she died suddenly at home. Necropsy showed a small atrial septal defect and a larger ventricular septal defect of $1.5 \mathrm{~cm}$ in the membraneous portion of the interventricular septum. There was right ventricular hypertrophy with some changes of pulmonary vascular disease. The actual cause of death was bronchopneumonia.

Case 2, a boy, was born to the same parents. There had been no pregnancies between his and his older sister's birth. He was born prematurely at 34 weeks' gestation with a birth weight of $1360 \mathrm{~g}$ (3rd centile), length $41 \mathrm{~cm}$ (3rd centile), and a head circumference of $31 \mathrm{~cm}$ (50th centile). $\mathrm{He}$ had initial respiratory distress which required three

Received for publication 23 May 1988.

Revised version accepted for publication 4 January 1989. days of assisted ventilation. He then developed heart failure and was transferred to a specialist cardiology centre where he was found to have a ventricular septal defect, secundum atrial septal defect, and a patent ductus arteriosus. He responded to treatment with diuretics.

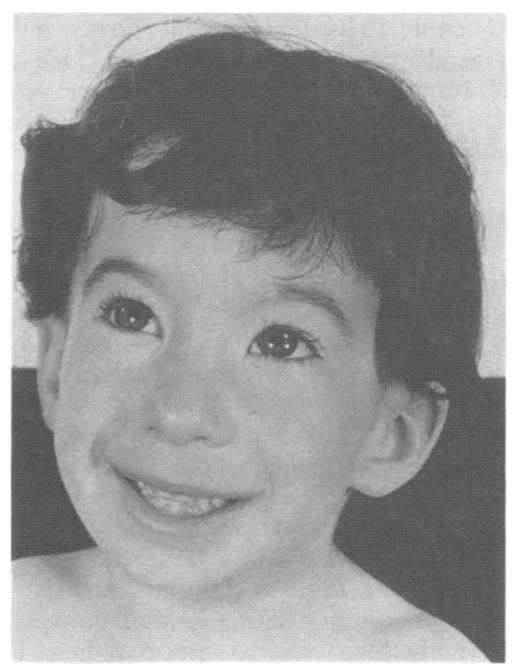

FIG 1 Case 1 at three years showing epicanthic folds, small nose, long philtrum, narrow upper lip, and low set, posteriorly rotated ears.

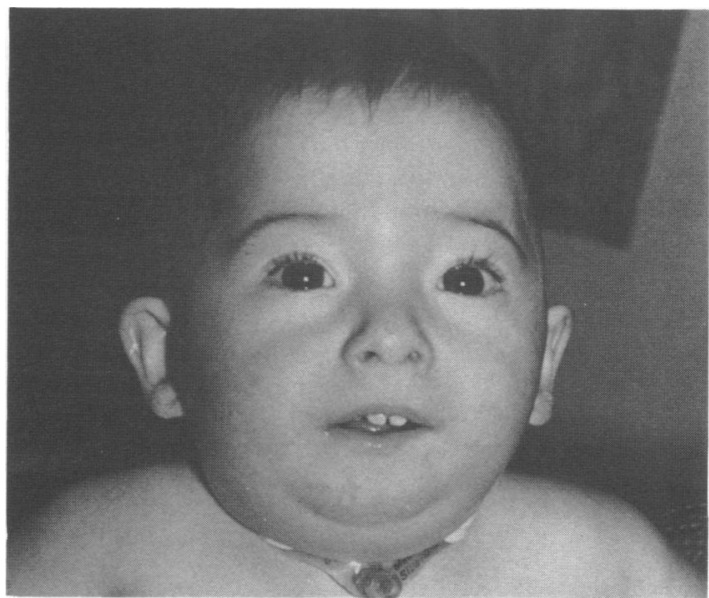

FIG 2 Case 2 at 18 months. Note similar facial features to his sister. Tracheostomy to prevent further airway obstruction. 
When reviewed at five months of age he had failed to grow satisfactorily. His weight was $3.5 \mathrm{~kg}(1.5 \mathrm{~kg}<3 \mathrm{rd}$ centile), length $58 \mathrm{~cm}$ (3rd centile), and OFC $37.8 \mathrm{~cm}$ $(2 \mathrm{~cm}<3$ rd centile).

The following features were noted on examination: prominent epicanthic folds, long philtrum, high palate, micrognathia, a narrow upper lip, and low set, posteriorly rotated ears. He was having intermittent upper airway obstruction. A choanogram showed bilateral choanal hypoplasia with stenosis and he required a tracheostomy to prevent further episodes of upper airways occlusion.

At review at two years he was still of short stature. His weight was $7.25 \mathrm{~kg}(2.5<3 \mathrm{rd}$ centile) and his OFC $44 \mathrm{~cm}$ ( $2 \mathrm{~cm}<3 \mathrm{rd}$ centile). His development showed mild global delay. His facial appearance is shown in fig 2 . He had short fingers with broad, flat nails. His chromosome analysis on two occasions has shown a normal 46,XY male karyotype. The parents have had no further children.

\section{Discussion}

The differential diagnosis of a child with congenital heart disease, growth failure, and mental retardation includes the effects to the fetus caused by maternal ingestion of hydantoin, valproate, and alcohol, Williams's syndome, ${ }^{1}$ the CHARGE association, ${ }^{2}$ and the Smith-Lemli-Opitz (SLO) syndrome. ${ }^{3}$ However, the mother took no drugs or alcohol during the pregnancies and both Williams's syndrome and the CHARGE association are sporadic. SLO is an autosomal recessive condition, but the development of the two children reported here is better than that seen in SLO, the facial appearance is different, and the affected boy reported here did not have a genital anomaly.

We believe the two children reported here have the same syndrome. It is likely that the girl who died had mild choanal stenosis because she had significant problems in feeding and sucking in the first few months of life. The main features of this condition are, therefore, short stature, microcephaly, mild to moderate developmental delay, atrial and ventricular septal defects, choanal stenosis, and a distinctive facial appearance with marked epicanthic folds, a small nose, long philtrum, and narrow upper lip. The parents are not related. We propose an autosomal recessive mode of inheritance for this syndrome, though a submicroscopic chromosomal abnormality or germ line mosaicism for an autosomal dominant condition cannot be excluded at present.

J A Hurst*, A C Berry $†$, And M A Tettenborn $\ddagger$ *Department of Paediatric Genetics, Institute of Child Health, 30 Guilford Street, London WCIN IEH; tDepartment of Genetics, Paediatric Research Unit, Division of Medical and Molecular Genetics, United Medical and Dental Schools, Guy's Hospital, London SE1 9RT; and $\ddagger$ Department of Paediatrics, District General Hospital, King's Drive, Eastbourne,

\section{References}

1 Williams JCP, Barratt-Boyes BG, Lowe JB. Supravalvular aortic stenosis. Circulation 1961;24:1311-8.

2 Hall BD. Choanal atresia and associated multiple anomalies. J Pediatr 1979;95:395-8.

${ }^{3}$ Smith DW, Lemli L, Opitz JM. A newly recognized syndrome of multiple congenital anomalies. J Pediatr 1964;64:210-7.

Correspondence to Dr J A Hurst, Department of Paediatric Genetics, Institute of Child Health, 30 Guilford Street, $\overrightarrow{0}$ London WC1N 1EH.

\section{Frontonasal dysplasia, congenital heart defect, and short stature: $\mathrm{a}$ \% further observation}

SUMmARY We present a mildly retarded boy with fronto- 윽 nasal dysplasia, valvular aortic stenosis, short stature, and $\vec{c}$

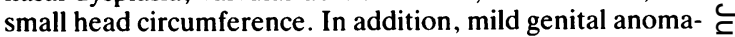
lies and bilateral Sydney lines were present. Strikingly $\stackrel{\mathbb{D}}{\bar{D}}$ similar cases recently published by de Moor et $a l^{1}$ suggest a defined clinical entity.

\section{History}

Prenatal. Low oestriol levels in third trimester, caesarean section at 35 weeks of gestation. Male newborn, small and light for dates.

Family. First child of healthy, non-consanguineous parents aged 33 years (mother) and 35 years (father). Healthy, one $\overrightarrow{\bar{O}}$ year old sister.

\section{Clinical examination}

At birth. Length $41 \mathrm{~cm}$ (3rd centile), weight $1810 \mathrm{~g}$ (10th centile), head circumference $29.5 \mathrm{~cm}$ (3rd centile). Hypertelorism with telecanthus, very broad nasal bridge, and $\overline{0}$ broad, flat nasal tip. Small penis.

At two years two months. Length $80 \mathrm{~cm}(-3 \mathrm{SD})$, weight $9.5 \mathrm{~kg}$ (3rd centile in relation to length), head circumference $45.5 \mathrm{~cm}(-2.6 \mathrm{SD}$ for age, $-2 \mathrm{SD}$ in relation to length). Round face with small skull, hypertelorism with $\frac{D}{2}$ telecanthus (inner canthal distance $30 \mathrm{~mm}, 97 \mathrm{th}$ centile in relation to head circumference). Broad and flat nasal $\mathrm{N}$ bridge with very broad and flat tip. Loud systolic murmur. or Small penis, shawl scrotum, testes descended. Sydney lines $N$ bilaterally. Psychomotor development slightly retarded.

Radiograph of the left hand showed markedly retarded skeletal maturation, corresponding to six months of age.

\section{Medical history}

Early infancy complicated by apnoeic episodes and fre- $T$ quent vomiting, improving gradually. Congenital heart $\bar{O}$ defect suspected; later valvular aortic stenosis diagnosed

Received for publication 15 November 1988.

Revised version accepted for publication 3 January 1989. 